\title{
Studies Concerning the Influence of the Wave Farms on the Nearshore Processes
}

\author{
Andrei Tănase Zanopol*, Florin Onea, Eugen Rusu \\ Department of Mechanical Engineering, University “Dunarea de Jos" of Galati, Galati, Romania \\ Email: ${ }^{*}$ andrei.zanopol@gmail.com
}

Received 6 April 2014; revised 3 May 2014; accepted 26 May 2014

Copyright (C) 2014 by authors and Scientific Research Publishing Inc.

This work is licensed under the Creative Commons Attribution International License (CC BY).

http://creativecommons.org/licenses/by/4.0/

(c) (i) D Den Access

\section{Abstract}

The main objective of the present work is to evaluate the impact on the nearshore waves and coastal processes of a generic wave farm. The target area considered is in the Romanian nearshore, in the vicinity of the Mamaia sector, coastal environment usually subjected to a strong erosion process. A picture of the wave conditions in this coastal environment is first provided by analyzing some in situ data registered at the Gloria drilling unit, which operates offshore the area of interest at about 50 meters water depth. A high resolution numerical modeling framework was implemented in the target area. This is based on the SWAN spectral model (Simulating Waves Nearshore) for waves and the 1D circulation model SURF (or the Navy Standard Surf Model) to assess the nearshore currents. The presence of the farm in the computational domain was represented by using the command obstacle, which is available in SWAN, and considering various transmission and reflection coefficients. Different wave farm configurations have been considered by adjusting the transmission and the reflection coefficients associated with the wave farm, between a no farm scenario and a fully developed project (corresponding to the case of total absorption). The influence of the farm on the wave field was quantified by performing analyses in the geographical space concerning the variability of the significant wave height. The results look interesting and they indicate that besides the production of the electric power, the presence of the wave farms may have a positive influence on controlling the coastal processes, reducing the erosion and giving in general more stability to the coastal environment, especially during the extreme storm conditions.

\section{Keywords}

Black Sea, Wave Farms, Energy, SWAN, Coastal Processes

\footnotetext{
${ }^{*}$ Corresponding author.
} 


\section{Introduction}

The world's ocean covers almost 70\% of the earth's surface, being already considered a suitable environment to extract energy from the natural resources (ex: wave, wind or maritime currents) especially in the vicinity of the coastlines characterized by shallow water areas. Beside the offshore wind industry, which is a leader in this sector, there is interest in harnessing the wave power if we consider the specific features of the waves (consistency, predictability and higher energy density) and also the large number of wave energy converters (WEC) available today [1].

In general, the offshore environment is suitable for the wave energy extraction because of the higher wave conditions, and it also was highlighted that the inland seas can provide viable conditions for such projects, as is the case of the Black Sea. A great number of studies have shown that the northwestern part of the Black Sea basin is characterized by significant wave conditions similar to those from the North-Sea or of the Baltic Sea (especially during the winter time), while for the wave energy it were noticed more energetic conditions in this area than in the other parts of the sea [2]-[4]. Since the northwestern part of the Black Sea is defined by a shelf area, where the water depths do not exceed $50 \mathrm{~m}$, this will create opportunities for the marine energy extraction. Although the fetch area is much smaller than in an open-ocean region, strong storm conditions can be reported affecting in this way both the marine transportation and the shoreline configuration [5]-[8].

If we discuss about the coastal stability, the Romanian nearshore area is severely affected by the erosion processes. Significant beach losses were reported in almost $60 \%-80 \%$ of the entire shoreline area, which only in the vicinity of the Danube Delta represent almost 2400 ha $(\approx 80$ ha/year) of beach areas that disappeared during the last 35 years. The northern sector of the coastline is characterized by fast erosion processes of the lower beach areas, which lead to the retreat of the shoreline with a rate of $10 \mathrm{~m} /$ year and generate seasonal sand bars accumulations [9]. Based on the Bruun rule it was possible to estimate the evolution of this sector (in long terms) considering an increase of the water level with $0.1 \mathrm{~m}$ until the year $2040 \mathrm{in}$ an average scenario (and with $0.3 \mathrm{~m}$ until 2040 in an extreme scenario). The first scenario indicated an erosion of $9 \mathrm{~m} /$ year for the sector Perisor-Periteasca, being followed by the sector Sulina-Sacalin with almost $7.5 \mathrm{~m} /$ year, while for the Cap Midia a value of $5.3 \mathrm{~m} /$ year it is considered to be dominant. For the second scenario, it was noticed that the sector Perisor-Periteasca can report a retreat of the shoreline with almost $27 \mathrm{~m} /$ year, and a $23 \mathrm{~m} /$ year was accounted by the Sulina-Sacalin sector [10].

Usually in the coastal areas the balance between the erosion and accretion processes influences the distribution of the sediment volumes. Since the Danube River is the main source of sediments from this region, during the last decades a particular issue in the Romanian area was that the sediment transport was significantly reduced due to several dam projects and also due to the consolidation of the main harbor areas. Because of this, the beach areas are not able to naturally replace the material lost in the sea. The nearshore currents can also influence the beach configuration by transporting the sediment particles along the shoreline throughout the action of the longshore currents [11]-[13].

Considering the current stage of the WEC systems and on the other hand the erosion problems reported in the Romanian coastal area, the purpose of this work is to identify the transformation of the wave and nearshore currents in the presence of a generic wave farm, which could be considered an alternative for the coastal protection.

\section{Methods and Materials}

Figure 1 presents the main geographical features of the Mamaia sector, which is located in the western part of the Black Sea basin. For this sector, it can be noticed that the shoreline is mainly oriented to the northwest direction (reported to nautical convention), on a $32^{\circ}$ angle from the north direction $\left(0^{\circ}\right)$. In Figure 1 (a) is also illustrated the offshore Gloria drilling platform, which operates in the vicinity of the selected target area $\left(44^{\circ} 31^{\prime} \mathrm{N}\right.$, $29^{\circ} 34^{\prime} \mathrm{E}$ ) in a water depth of $50 \mathrm{~m}$. The in situ wave data provided by this station covers the time interval January 2003-December 2009 (seven years), and provides daily measurements of the wave characteristics reported to a $6 \mathrm{~h}$ interval (01-07-13-19 UTC). Also, it is important to mention that for this study, the significant wave height (Hs) was mainly considered for the analysis, this parameter being considered in the identification of the case studies.

The simulations were carried out by using the Interface for SWAN and Surf Models (ISSM) which combines two numerical models: a) for the waves-SWAN (Simulating Waves Nearshore); b) for the longshore currents-NSSM (Navy Standard Surf Model) [14]-[16]. The main philosophy of this system is that the SWAN 

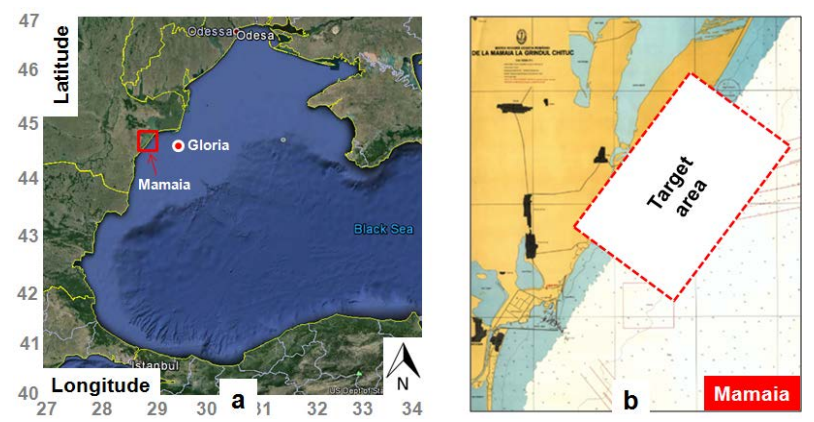

Figure 1. (a) The western side of the Black Sea; (b) Map of the target area (Mamaia) located in the western part of the Black Sea basin.

model can identify the transformation of the incoming waves in the geographical space, providing in this way important information about the wave characteristic at the entrance in the surf area, which will be further use by the NSSM model to predict the nearshore currents circulation.

Regarding the SWAN model, this was already implemented and extensively tested in the entire Black Sea area, the accuracy of this prediction system being identified throughout the validation with in situ and remotely sensed data, as discussed in [17]-[19]. It is considered to be a state of the art wave model which solves the spectral energy balance equation, being focused on the evaluation of the wave spectrum in time, spectral and geographical spaces [20]. This is based on the action density spectrum $(N)$ since in the presence of the currents the action density it is conserved, while the energy density $(E)$ is not. Based on this, it can be mentioned that the spectral action balance equation is equal to the energy density divided by the relative frequency $(\sigma)$, as follows:

$$
\frac{\partial N}{\partial t}+\nabla\left[\left(\vec{c}_{g}+\vec{U}\right) N\right]+\frac{\partial}{\partial \sigma} c_{\sigma} N+\frac{\partial}{\partial \theta} c_{\theta} N=\frac{S}{\sigma}
$$

where $\theta$ is the wave direction and $\vec{U}$ the velocity of the ambient current which is considered uniform with respect to the vertical coordinate. The propagation velocities of the wave energy are the group velocity $\vec{c}_{g}$ in the physical space $\left(\vec{c}_{g}=\partial \sigma / \partial \vec{k}\right)$ with $k$ is the wave number associated with the relative frequency, $c_{\sigma}=\dot{\sigma}$ and $c_{\theta}=\dot{\theta}$ in the spectral space. In deep water, the source $(S)$ comprises three primary components: the atmospheric input (Sin), the white capping dissipation (Sdis) and the nonlinear quadruplet interactions (Snl). In shallow water, additional phenomena like bottom friction, depth induced wave breaking and triad nonlinear wave-wave interactions induced by the finite depth effects $(S f d)$ should be also considered.

The Surf Model [21] can define the cross shore variations of the longshore current. Some other surf parameters can be also evaluated based on the SWAN direct input. The following equation computes the longshore currents:

$$
\tau_{y}^{r}+\rho \frac{\partial}{\partial x}\left[\mu h \frac{\partial V}{\partial x}\right]-\left\langle\tau_{y}^{b}\right\rangle+\left\langle\tau_{y}^{w}\right\rangle=0
$$

where $\tau_{y}^{r}$ represents the longshore directed radiation stress due to the incident waves, the next term expresses the effect of the horizontal mixing term due to cross-shore gradients in the longshore current velocity, $\tau_{y}^{b}$ represents the wave averaged bottom stress and finally $\tau_{y}^{w}$ is the long-shore wind stress. A parametric relationship for cross shore growth and dissipation of waves due to breaking is also included into the model.

The computational domain considered in the present work is presented in Figure 2, where this is defined by a rectangular area with a length of $9 \mathrm{~km}$ in $x$-direction (cross shore) and $14 \mathrm{~km}$ in $y$-direction (long shore). In the background is presented the bathymetry of the target area where a maximum depth of $20 \mathrm{~m}$ can be observed, while in the foreground the generic wave farm is presented together with some reference points which will be used to assess the evolution of the wave characteristic for various scenarios. The wave farm has a length of $6 \mathrm{~km}$ and is positioned in the center of the target area at approximately $4 \mathrm{~km}$ from the shoreline, being parallel to the coastline.

In order to identify various wave farm configurations, several transmission scenarios were considered throughout 


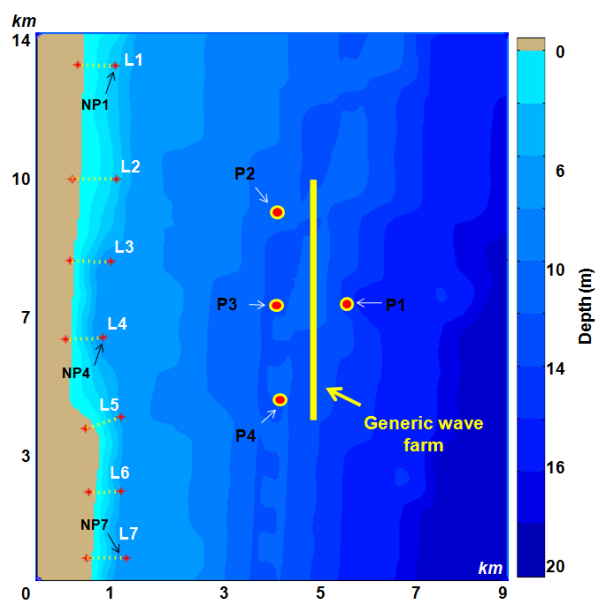

Figure 2. The Mamaia computational domain considered for the numerical simulations. In the background the bathymetry is represented while in foreground the location of the generic wave farm. The reference points and the reference lines are: P1, P2, P3 and P4-offshore points; L1-L7 reference lines considered in the analysis of the nearshore currents, each offshore extremity point of the reference lines is denoted as a nearshore point (NP1-NP7).

the activation of the command obstacle in SWAN, and the properties of the generic wave farm were shifted from a no farm scenario (total transmission of the waves) to a fully developed project (total absorption). They are denoted as:

- T1-No wave farm-100\% wave transmission;

- T2-A spaced WEC layout-75\% wave transmission (realistic scenario);

- T3-A narrow spaced WEC layout-50\% wave transmission;

- T4-A highly absorber wave farm-25\% wave transmission (optimistic scenario);

- T5-Ideal wave farm (total absorption)— $0 \%$ wave transmission.

In order to provide numerical information regarding the evolution of the wave parameters in the presence of the wave farm, several reference points and lines were considered. The group points P1-P4 are used to identify the wave characteristics of the offshore area, with the mention that the point P1 is located in front of the wave farm being unaffected by any variation. From the coastline area seven reference lines (L1-L7) were used to identify the evolution of the longshore currents, while their offshore extremities (denoted from NP1 to NP7) are considered to indicate the evolution of the incoming waves in the shallow water area.

\section{Results}

In Figure 3(a) the monthly values of several statistical indexes, as: mean value, $95^{\text {th }}$ percentiles (denoted as $95^{\text {th }}$ ) and the extreme value, of the $H$ s parameter are presented. It can be noticed that the average values can exceed during the wintertime (considered from October to March) $1.4 \mathrm{~m}$, while a maximum of $1.78 \mathrm{~m}$ can be encountered in January. In the summer time, these values are much lower being reported in the interval 0.82 - $1.34 \mathrm{~m}$, with a maximum in September. For the 95 percentiles, the differences between the summer and winter time are clearer, with a maximum of 5.11 m observed in January and February. During the winter time, the extreme values, which can be associated with the storm conditions, report $8.5 \mathrm{~m}$ in January and a minimum of $3.5 \mathrm{~m}$ in July. From the evolution of the Tm parameter (Figure 3(b)) it can be noticed that the mean value is located in the interval 4.11 - $5.08 \mathrm{~s}, 95^{\text {th }}$ percentiles between 6.6 - $7.62 \mathrm{~s}$ while for the extreme values a maximum of $9.4 \mathrm{~s}$ can occur during January and March.

Regarding the parameter $H s$, this is reported for the total time and the winter time. In general the wave heights are located in the interval $0.5-2 \mathrm{~m}$, with the mention that during the winter time the wave conditions from the classes 1.5 - $2 \mathrm{~m}$ are more significant than those from the interval $0.5-1 \mathrm{~m}$. 


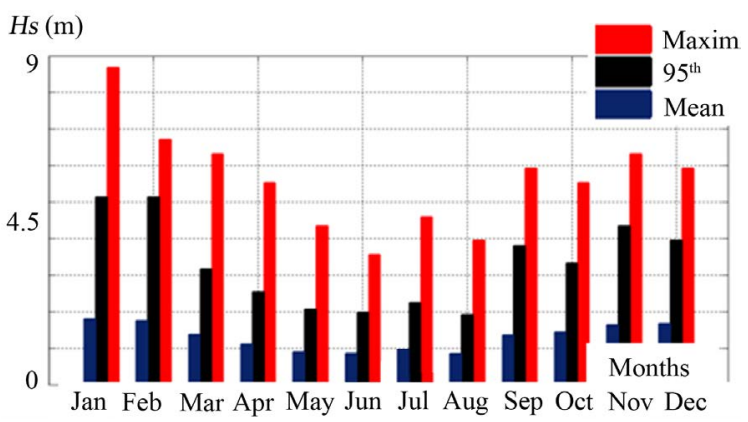

(a)

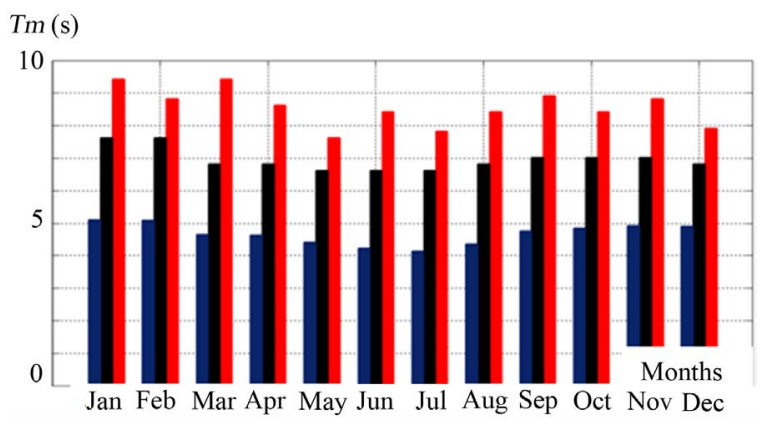

(b)

Figure 3. Wave statistics based on the data coming from the Gloria station. In situ measurements covering the time interval January 2003-December 2009, where: (a) and (b) Monthly evolution of the parameters $H s$ and $\mathrm{Tm}$, respectively indicated in terms of mean values, $95^{\text {th }}$ percentiles and maximum values.

Based on this statistical analysis of the $H s$ and $T m$ parameters, it was possible to identify three case studies which will be used as an input conditions for the SWAN numerical simulations. They are denoted as:

- CS1: $\mathrm{Hs}=1.3 \mathrm{~m} ; \mathrm{Tm}=4.6 \mathrm{~s}$-average wave conditions;

- CS2: $\mathrm{Hs}=3.9 \mathrm{~m} ; \mathrm{Tm}=7.2 \mathrm{~s}$-energetic wave conditions;

- CS3: $H s=8.7 \mathrm{~m} ; \mathrm{Tm}=9.4 \mathrm{~s}$ - extreme situation (storm events).

Since the Gloria station is located in the offshore area, it was not suitable to consider the wave directions from this location since this will not be relevant to the Mamaia sector (due to refraction process that dominates the nearshore wave propagation). Based on the fact that the incident wave fields can rotate in the geographical space due to the interaction with the seabed, in the absence of the nearshore in situ wave measurements, three wave directions were considered for the analysis: northeast $\left(30^{\circ}\right)$ —denoted as NE waves; east $\left(90^{\circ}\right)$ —E waves; southeast $\left(150^{\circ}\right)$-SE waves. All these directions were reported to the nautical convention.

Although the analysis was performed for all the three case studies, in the next sections only the results for CS1 and CS3, which are more relevant, will be presented.

\subsection{Influence of the Generic Wave on the Local Wave Conditions}

In the absence of the wave farm (case T1) can be noticed in the central part of the target area (offshore area) the presence of a wave field which reports values between $0.6 \mathrm{~m}$ and $1 \mathrm{~m}$. The orientation of this wave field is mainly determined by the direction of the incoming waves, with the mention that in the case of the northeast and southeast waves the wave fields from the vicinity of the shoreline present a triangle shape, while for the waves coming from the east this is orientated parallel to the coastline presenting a wide of $3 \mathrm{~km}$. In the presence of the two wave farm transmission scenarios (T3 and T5), it can be noticed an extension of the wave field from the shoreline to the vicinity of the wave farm and also the occurrence of a new wave field (only for T5) which presents values in the interval $0.2-0.4 \mathrm{~m}$ and links the wave farm to the shoreline in the case of the northeastern and southeastern waves, respectively.

Going from the energetic to the extreme conditions (study case CS3) it can be noticed the occurrences of the multiple wave height fields in the target area, which are parallel to the coastline, are characterized by a maximum of $8.7 \mathrm{~m}$ in the offshore area and of $5 \mathrm{~m}$ in the vicinity of the wave farm (in front).

In Figure 4, the interactions of the incoming waves with the wave farm (reported to a $2 \mathrm{~km}$ distance between the points P1 and P3) are presented for the case studies CS1 and CS3. For the study case CS1 a significant variations can be noticed for the wave heights, which for the northeastern waves mean a variation from $1.1 \mathrm{~m}$ to 0.7 $\mathrm{m}$ (T3) and $0.4 \mathrm{~m}$ (T5), reporting a local regeneration of the wave field. The eastern waves are reduced from 1.2 $\mathrm{m}$ to $0.6 \mathrm{~m}$ (T3) and to $0.2 \mathrm{~m}$ (T5) only in the proximity of the wave farm. A similar evolution to the northeastern waves is observed in the case of the southeastern waves, with the observation that for the T3 scenario the waves can be reduced to $0.6 \mathrm{~m}$.

Regarding the study case CS3 in the absence of the wave farm (T1) it can be mentioned a constant decrease of the wave heights from $4.5 \mathrm{~m}$ to $3 \mathrm{~m}$ (NE and $\mathrm{SE}$ waves) and from $5 \mathrm{~m}$ to $3.7 \mathrm{~m}$ (E waves). The presence of the wave farm can reduce the initial wave heights to: $2 \mathrm{~m}$ (T3) and $0.8 \mathrm{~m}$ (T5)—NE waves; $2.2 \mathrm{~m}$ (T3) and $0.1 \mathrm{~m}$ (T5) —E waves; $3 \mathrm{~m}$ (T3) and $2.3 \mathrm{~m}$ (T5) - SE waves. 


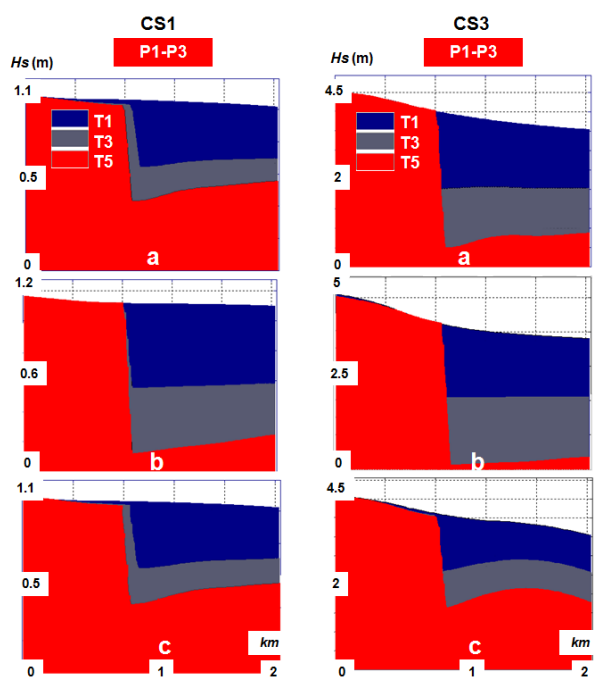

Figure 4. Evaluation of the $H s$ variation along the line defined by the reference points P1-P3 which is defined for the case studies CS1 and CS3 considering two transmission scenarios (T1, T3 and T5), where: (a) NE waves; (b) E waves; (c) SE waves.

In Table 1 a numerical assessment of the wave parameters (Hs, Tm and Dir) from the vicinity of the coastline is provided by using the NP control points for the case study CS1, considering only the scenario T1 (without wave farm). It can be mentioned that the point NP2 is located in water depth of $2.5 \mathrm{~m}$, compared to NP7 where a value of $5.2 \mathrm{~m}$ is reported and that is why higher values can be encountered in the last case.

Analyzing the evolution of the $\mathrm{Hs}$ parameter, it can be noticed that for the NE waves a maximum of $0.92 \mathrm{~m}$ is indicated by the NP1, while similar values or even higher than $1 \mathrm{~m}$ can occur in the lower part of the target area (point NP7) for the E and SE waves. The wave period Tm reports values under $3 \mathrm{~s}$ for the SE waves, with the mention that a value of $3.2 \mathrm{~s}$ is indicated by the point NP7. Compared to the initial wave direction $\left(30^{\circ}, 90^{\circ}\right.$ and $150^{\circ}$ ) there can be noticed large differences of the Dir parameter, which presents values in the range of $55.3^{\circ}$ $65.3^{\circ}$ (SE waves); can exceed $100^{\circ}$ in the lower part of the target (E waves); and can report values below $150^{\circ}$ (SE waves) with a minimum of $116^{\circ}$ for the point NP1.

Figure 5 presents the differences between the scenario T1 (no wave farm) and the scenarios T2-T5 for the case study CS1. These variations are indicated by using the $\Delta$ symbol together with the wave parameter and the number of each scenario case (ex: T2- $\Delta 2, \mathrm{~T} 3-\Delta 3, \mathrm{~T} 4-\Delta 4$ and T5- $\Delta 5$ ). Considering the significant wave heights $H s$, it can be noticed that in the case of the NE waves the differences are insignificant, while for the points NP4 and NP5 these values can reach $0.25 \mathrm{~m}$ (for T5) and $0.17 \mathrm{~m}$ (for T3). Regarding the E waves, much smaller values are reported in the upper part of the target area, while in the central part the points NP3 and NP4 present values of $0.35 \mathrm{~m}$ (T5) and $0.12 \mathrm{~m}$ (T2), which means a percent of $40 \%$ and respectively $14 \%$ from the initial values (T1). For the SE waves, much higher differences are noticed close to point NP2 for the scenarios T4 and $\mathrm{T} 5$, where a value of $0.32 \mathrm{~m}(43 \%)$ is reported, while for the scenario T2 the same point indicates a value of 0.13 $\mathrm{m}$. A gradual decrease of the values is noticed in the lower part of the target area, where the points NP5-NP7 reveal differences close to zero.

Regarding the $T m$ parameter this presents an evolution similar to the one reported for the wave heights. For the NE waves it can be noticed that the points NP1 and NP2 indicate no significant variations, while in the upper part of the target area a maximum of $0.64 \mathrm{~s}$ is indicated by the NP 5 (T5) and a minimum of $0.14 \mathrm{~s}$ by the NP4 and NP6 (T2). For the E waves, much higher values are noticed close to the points NP3 and NP4, which present values in the range of $0.69-0.74 \mathrm{~s}$ (T5) and also values of $0.13-0.18 \mathrm{~s}$ (T2). The point NP2 presents the largest differences when the waves occur from the southeast, which start from $0.26 \mathrm{~s}(9 \%)$ and reach $0.85 \mathrm{~s}(29 \%)$ being reported from the scenario $\mathrm{T} 2$ to $\mathrm{T} 5$.

Considering the wave direction, when the waves occur from northeast, much lower values are reported in NP1 and NP2, where major variations can occur in the central part of the target area which can reach $19.8 \%$ for the point NP4 and NP5, respectively. The incoming NE waves can change their directions with almost $6^{\circ}$ (over $30^{\circ}$ ) 


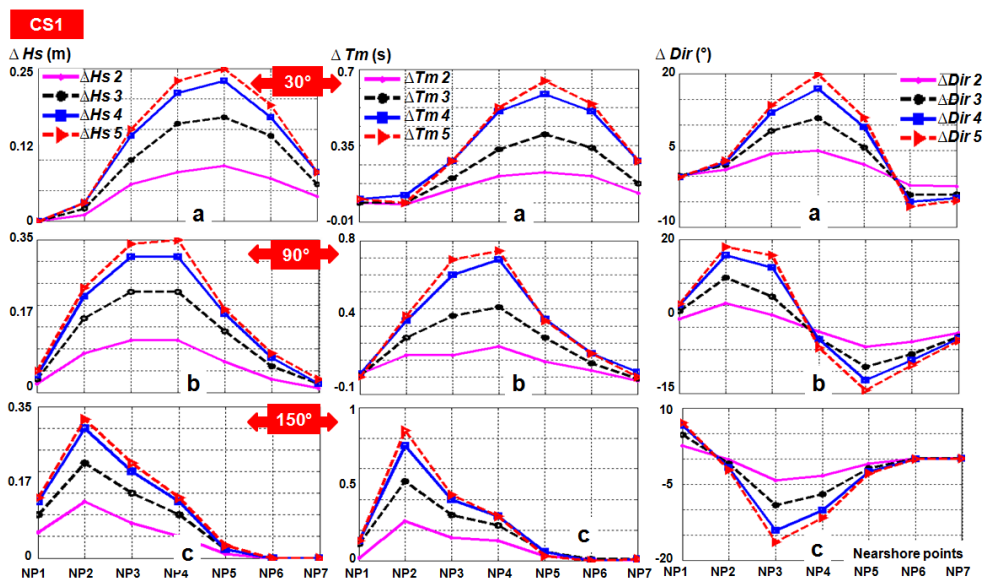

Figure 5. Wave parameters as resulted in the points NP for the case study CS1 considering waves coming from NE, E and SE, respectively, where the subplots present: (a) Hs variations corresponding to the transmission cases T2-T5; (b) Tm variations corresponding to the transmission cases T2-T5; (c) Dir variations corresponding to the transmission cases T2-T5.

Table 1. Wave parameters reported in the nearshore control points (NP1-NP7) for the case study CS1. The results are presented only for the transmission case T1 (without wave farm).

\begin{tabular}{|c|c|c|c|c|c|c|c|c|}
\hline Characteristics & Direction & NP1 & NP2 & NP3 & NP4 & NP5 & NP6 & NP7 \\
\hline \multirow[t]{2}{*}{ Depth (m) } & $\downarrow$ & 2.70 & 2.53 & 4.76 & 4.92 & 4.31 & 4.27 & 5.23 \\
\hline & $30^{\circ}$ & 0.92 & 0.77 & 0.73 & 0.74 & 0.72 & 0.73 & 0.75 \\
\hline \multirow[t]{3}{*}{$\begin{array}{c}H s \\
\text { (m) }\end{array}$} & $90^{\circ}$ & 0.93 & 0.88 & 0.87 & 0.87 & 0.89 & 0.94 & 1.03 \\
\hline & $150^{\circ}$ & 0.69 & 0.74 & 0.77 & 0.73 & 0.83 & 0.91 & 1.16 \\
\hline & $30^{\circ}$ & 3.34 & 3.17 & 3.01 & 3.02 & 2.92 & 3.00 & 3.06 \\
\hline \multirow[t]{3}{*}{$\begin{array}{l}T m \\
\text { (s) }\end{array}$} & $90^{\circ}$ & 3.28 & 3.20 & 3.01 & 3.01 & 3.00 & 3.13 & 3.24 \\
\hline & $150^{\circ}$ & 2.87 & 2.86 & 2.79 & 2.70 & 2.87 & 2.96 & 3.20 \\
\hline & $30^{\circ}$ & 55.30 & 65.29 & 62.70 & 57.57 & 59.43 & 61.09 & 59.32 \\
\hline \multirow[t]{2}{*}{$\begin{array}{l}\text { Dir } \\
\left(^{\circ}\right)\end{array}$} & $90^{\circ}$ & 86.06 & 93.02 & 93.75 & 88.46 & 90.98 & 94.85 & 100.20 \\
\hline & $150^{\circ}$ & 115.94 & 116.10 & 125.31 & 117.17 & 121.71 & 129.24 & 147.34 \\
\hline
\end{tabular}

for the scenarios $\mathrm{T} 4$ and $\mathrm{T} 5$.

For the E waves a maximum $18.3^{\circ}$ is reported by NP2 for the scenario T5, while for the values higher than $90^{\circ}$ the point NP5 indicates a maximum $14.3^{\circ}$ for the scenario T5. The SE waves can also generate negative values of the wave direction, in this case the highest value being reported for the NP3 while a minimum is more common to the points NP5-NP7.

In Table 2 and Figure 6 the evolution of the main wave parameters for the case study CS3 are presented. In the absence of the wave farm (T1), the Hs parameter indicates a much smaller value for the points NP1 and NP2 while in the lower part of the target area the point NP7 indicates a value of $2.3 \mathrm{~m}$ (SE waves) followed by the point NP5 with $2 \mathrm{~m}$ (E and NE waves). From the analysis of the wave directions there can be observed values in the interval: $78.8^{\circ}-89.6^{\circ}$ (NE waves); $97^{\circ}$ - $130.2^{\circ}$ (E waves); $104.2^{\circ}-176.7^{\circ}$ (SE waves).

\subsection{Influence of the Generic Wave Farm on the Nearshore Currents}

The analysis is based on the identification of the maximum current velocities $\left(V c_{\max }\right.$ in $\left.\mathrm{m} / \mathrm{s}\right)$ along the reference lines L1-L7 considering NE, E and SE waves and also on the current profile $(V c)$ along the lines L1, L4 and L7. 


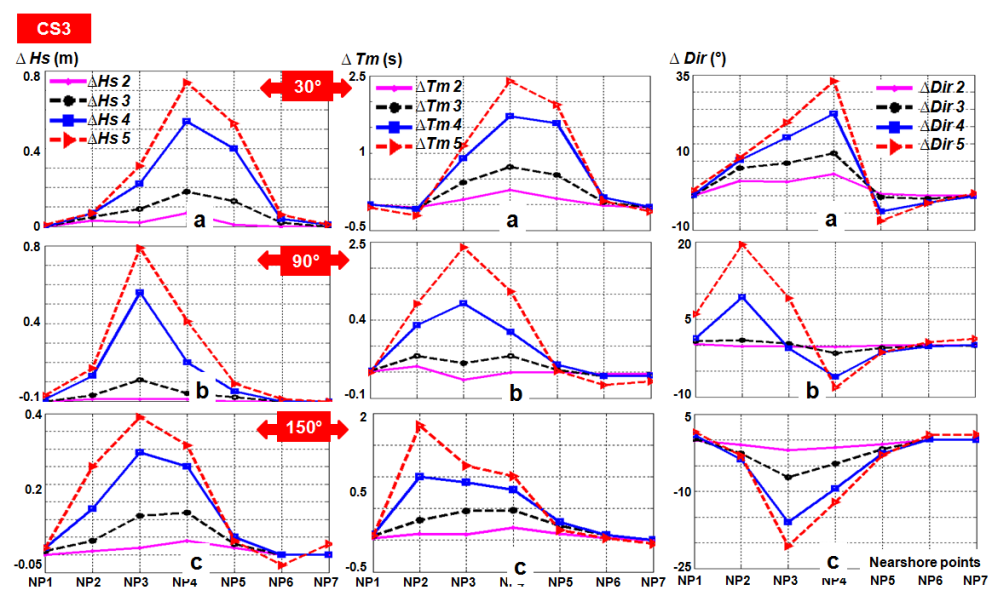

Figure 6. Wave parameters as resulted in the points NP for the case study CS3 considering waves coming from NE, E and SE, respectively, where the subplots present: (a) Hs variations corresponding to the transmission cases T2-T5; (b) Tm variations corresponding to the transmission cases T2-T5; (c) Dir variations corresponding to the transmission cases T2-T5.

Table 2. Wave parameters reported in the nearshore control points (NP1-NP7) for the case study CS3. The results are presented only for the transmission case T1 (without wave farm).

\begin{tabular}{cccccccccc}
\hline Characteristics & Direction & NP1 & NP2 & NP3 & NP4 & NP5 & NP6 & NP7 \\
\hline Hs (m) & $30^{\circ}$ & 1.34 & 1.37 & 1.75 & 1.90 & 2.00 & 1.91 & 1.96 \\
& $90^{\circ}$ & 1.50 & 1.45 & 1.87 & 1.89 & 2.07 & 1.95 & 2.21 \\
& $150^{\circ}$ & 1.46 & 1.43 & 1.86 & 1.74 & 1.84 & 1.53 & 2.32 \\
& $30^{\circ}$ & 7.88 & 8.10 & 7.81 & 7.71 & 8.03 & 7.89 & 7.67 \\
& $90^{\circ}$ & 8.56 & 8.59 & 7.61 & 7.81 & 8.27 & 7.89 & 7.42 \\
$\operatorname{Dir}\left(\mathbf{(}^{\circ}\right)$ & $150^{\circ}$ & 8.63 & 8.62 & 7.98 & 7.74 & 7.94 & 7.10 & 7.43 \\
& $30^{\circ}$ & 82.03 & 89.61 & 84.69 & 81.67 & 78.83 & 81.61 & 85.67 \\
& $90^{\circ}$ & 97.00 & 102.73 & 106.88 & 101.27 & 97.19 & 108.44 & 130.16 \\
& $150^{\circ}$ & 107.80 & 108.02 & 115.57 & 108.38 & 104.24 & 126.46 & 176.72 \\
\hline
\end{tabular}

It was considered relevant to identify the current profiles only for the NE and SE waves because they represent the main wave directions from which the longshore currents are more probably to be generated and in this way to influence more the local shoreline drift. It is possible to record negative values of the longshore currents, which would mean that they are oriented from north to south, but the maximum values will be reported in terms of the positive values in order to highlight the current evolution more clearly.

Analyzing the maximum current velocities for the NE waves, it can be noticed that the reference line L1 presents similar values for all the transmission scenarios, while for the rest of the line a decrease of the current velocities from the case T1 to T5 can be observed. A maximum value of $0.76 \mathrm{~m} / \mathrm{s}$ is reported for the line L3 (T1), which gradually decreases to $0.62 \mathrm{~m} / \mathrm{s}$ (T5). For the line L7 there is a difference of $0.04 \mathrm{~m} / \mathrm{s}$ between the cases $\mathrm{T} 1$ and $\mathrm{T} 5$. In the case of the $\mathrm{E}$ waves, it can be mentioned a decrease of the velocities from the T1 scenario to $\mathrm{T} 5$, which may vary between a maximum value of $0.62 \mathrm{~m} / \mathrm{s}$ for the line L3 (T1) and a minimum of $0.29 \mathrm{~m} / \mathrm{s}$ for L5 (T5). When the waves occur from the southeast sector, the lines L1 and L2 indicate an increase of the current velocities, L2 and L4 a reverse trend, while no significant variations are reported for the rest of the lines.

Considering the current profiles (Figure 7), it can be mentioned that in general the values are negative, except 
for the lines L3, L4 (T4 and T5), L6 and L7 in the case of the SE waves. The maximum values are reported in the offshore area, being noticed smaller differences between the current profiles for the lines L1 (NE waves) and L7 (SE waves), which also report much higher lengths of the profile lines. Also, it can be mentioned the line L4 (NE waves), where the transmission scenarios T4 and T5 may change slightly the current direction from south to north (positive values but close to zero). Considering the values provided by the line L7 (NE waves), it can be noticed that there is a good agreement between all the transmission scenarios, some differences occurring in the offshore area while close to the shoreline a velocity of about $0.1 \mathrm{~m} / \mathrm{s}$ can be considered dominant. In the vicinity of the shoreline, the currents generated by the northeastern waves can be considered to be more important for the coastal erosion than the one reported from southeast.

The evolution of the current velocities for the case study CS3 was also considered. By analyzing the maximum values, it can be mentioned that much higher values are observed than in the case studies CS1. For the NE waves, the reference lines L2, L3 and L7 indicate an increase of the current velocities (from T1 to T5) reporting a maximum of $1.33 \mathrm{~m} / \mathrm{s}$, while the lines L4, L5 and L6 indicate a decrease of the values and a maximum of 1.49 $\mathrm{m} / \mathrm{s}$ for the case $\mathrm{T} 1$.

In the case of the E and SE waves, it can be noticed a similar trend, with the increase of the values for the lines L1-L3 (from T1 to T5) and smaller variations along the L6 and L7, while a value of $0.75 \mathrm{~m} / \mathrm{s}$ is reported along the line L2 and L5 for the T1 scenario. The highest values are reported in the lower part of the target area where a maximum of $1.5 \mathrm{~m} / \mathrm{s}$ is indicated by the line $\mathrm{L} 7$ for all the transmission scenarios, which increases the erosion processes from the sector located south of Mamaia due to the action of the longshore currents (coming from north).

From the analysis of the current profiles, it can be mentioned that a much higher variation is observed in the central part of the target area while significantly higher values are observed in the offshore region. More details regarding the current profiles associated to the lines L1, L4 and L7 are provided in Figures 8(a)-(c).

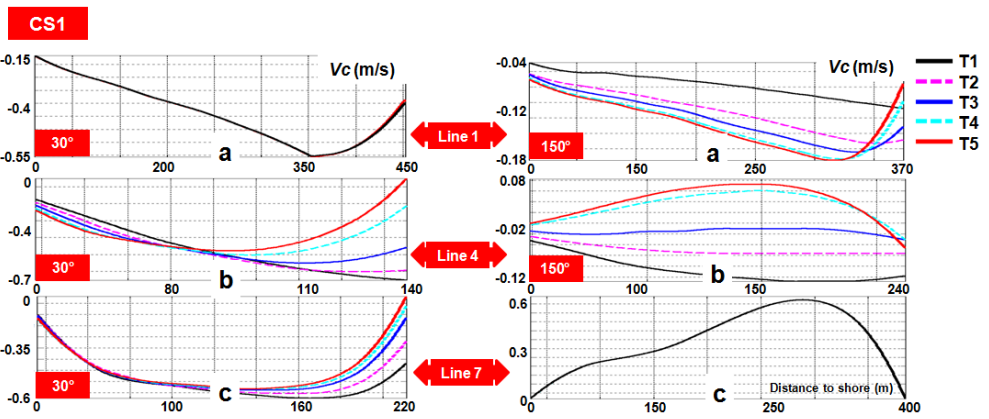

Figure 7. CS1, Nearshore current evolution in the presence of the wave farm considering NE, E and SE waves, respectively. The results are reported to all the transmission scenarios (T1-T5), where the subplots represent: (a) Vc variation along L1; (b) Vc variation along L4; (c) Vc variation along L7.

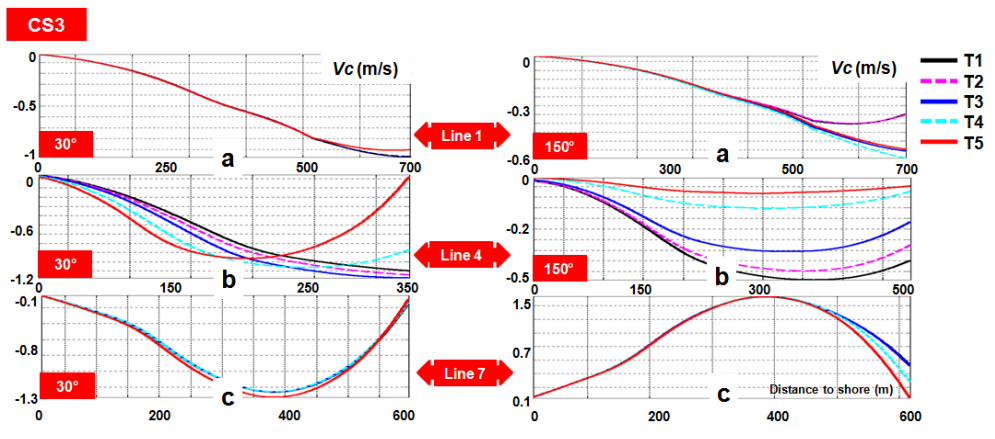

Figure 8. CS3, Nearshore current evolution in the presence of the wave farm considering NE, E and SE waves, respectively. The results are reported to all the transmission scenarios (T1-T5), where the subplots represent: (a) Vc variation along L1; (b) Vc variation along L4; (c) Vc variation along L7. 


\section{Conclusions}

The dynamics of the beach area is especially related to the erosion and accretion processes, which are influenced by the natural and anthropogenic factors. The erosion of the Romanian nearshore is considered to be a very serious issue and currently there are various projects designed to compensate the Danube sediments and also to protect the beach sector from the influence of the waves generated by the storm events. In close connection to the above aspects, the main objective of the present work was to provide a general picture of the possible coastal impact of a generic wave farm that would operate in the Mamaia sector.

Some relevant case studies (CS1 and CS3) were considered for performing SWAN simulations forced considering on the external boundary the results provided by the in situ wave measurements coming from the Gloria drilling unit, which cover the time interval January 2003-December 2009. Since in the northeast region of the Black Sea there is currently no wave energy project under implementation, and several scenarios were considered in order to identify how various wave farm projects can influence the local waves and current pattern, in order to provide a better protection for the shoreline area.

Considering the influence of the wave farm on to the local wave conditions, it was noticed that at the contact with the WEC systems the incoming waves can be reduced by almost $50 \%$ for the scenario T3 regardless of the wave direction, while much higher values are reported for T5. This is important because in this way a large amount of energy would be extracted from the waves, while in the vicinity of the coastline the wave energy will be significantly reduced, especially in the case of the short (but intense) storm events. Considering the numerical values provided in some reference points (denoted as NP) it can be noticed that, although the dissipative effects are dominant, in the shallow water areas the influence of the wave farm is visible in all the study cases (CS1 and CS3). It can be also noticed that in the presence of the wave farm the wave directions can significantly change, modifying in this way the erosion patterns.

As regards the wave induced nearshore currents, it was noticed that the presence of the wave farm can also increase sometimes the current velocities from the offshore area, while in the proximity of the shoreline there are no differences between the transmission scenarios (T1-T5). Based on these data it can be considered that the parallel alignment of the wave farm with the shoreline is suitable since it will reduce the incoming waves, but will not restrict the natural circulation of the sediments between various beach sectors.

The results are interesting since they indicate that a WEC project can be considered a viable alternative to the conventional solutions used for the coastal protection, especially for the Romanian nearshore.

\section{Acknowledgements}

This work was supported by a grant from the Ministry of National Education, CNCS-UEFISCDI, project number PN-II-ID-PCE-2012-4-0089 (project DAMWAVE). The second author also acknowledges the financial support of the project POSDRU/159/1.5/S/132397 "Excellence in research by doctoral and postdoctoral fellowships-ExcelDOC”.

\section{References}

[1] Diaconu, S. and Rusu, E. (2013) The Environmental Impact of a Wave Dragon Array Operating in the Black Sea. The Scientific World Journal, 2013, 1-20. http://dx.doi.org/10.1155/2013/498013

[2] Onea, F. and Rusu, E. (2014) Evaluation of the Wind Energy in the North-West of the Black Sea. International Journal of Green Energy, 11, 465-487. http://dx.doi.org/10.1080/15435075.2013.773513

[3] Rusu, E. and Onea, F. (2013) Evaluation of the Wind and Wave Energy along the Caspian Sea. Energy, 50, 1-14. http://dx.doi.org/10.1016/j.energy.2012.11.044

[4] Rusu, E. (2009) Wave Energy Assessments in the Black Sea. Journal of Marine Science and Technology, 14, $359-372$. http://dx.doi.org/10.1007/s00773-009-0053-6

[5] Rusu, E. (2010) Modeling of Wave-Current Interactions at the Danube’s Mouths. Journal of Marine Science and Technology, 15, 143-159. http://dx.doi.org/10.1007/s00773-009-0078-x

[6] Ivan, A., Gasparotti, C. and Rusu, E. (2012) Influence of the Interactions between Waves and Currents on the Navigation at the Entrance of the Danube Delta. Journal of Environmental Protection and Ecology, 13, 1673-1682. https://docs.google.com/a/jepe-journal.info/viewer?a=v\&pid=sites\&srcid=amVwZS1qb3VybmFsLmluZm98amVwZS 1qb3VybmFsfGd4OjQyMjM3OTNiNDk5ODZkMjU

[7] Gasparotti, C. and Rusu, E. (2012) Methods for the Risk Assessment in Maritime Transportation in the Black Sea Ba- 
sin. Journal of Environmental Protection and Ecology, 13, 1751-1760.

https://docs.google.com/a/jepe-journal.info/viewer?a=v\&pid=sites\&srcid=amVwZS1qb3VybmFsLmluZm98amVwZS 1qb3VybmFsfGd4OmU0NDZmNDgzMmJmN2E5OQ

[8] Rusu, L. (2010) Application of Numerical Models to Evaluate Oil Spills Propagation in the Coastal Environment of the Black Sea. Journal of Environmental Engineering and Landscape Management, 18, 288-295. http://www.tandfonline.com/doi/abs/10.3846/jeelm.2010.33\#.UzqoTqLr-t8 http://dx.doi.org/10.3846/jeelm.2010.33

[9] Eco Smart Management (2009) Raport de mediu plan integrat de dezvoltare al polului naţional de creştere.

[10] Halcrow Romania (2011) Master Plan: Protecţia şi reabilitarea zonei costiere. Asistenţă tehnică pentru pregătirea de proiecte, Reducerea eroziunii costiere.

[11] Rusu, E. and Macuta, S. (2009) Numerical Modelling of Longshore Currents in Marine Environment. Environmental Engineering and Management Journal, 8, 147-151. http://omicron.ch.tuiasi.ro/EEMJ/pdfs/vol8/no1/33_Rusu.pdf

[12] Rusu, E., Conley, D.C. and Coelho, E.F. (2008) A Hybrid Framework for Predicting Waves and Longshore Currents. Journal of Marine Systems, 69, 59-73. http://dx.doi.org/10.1016/j.jmarsys.2007.02.009

[13] Rusu, E. and Guedes Soares, C. (2010) Validation of Two Wave and Nearshore Current Models. Journal of Waterway, Port, Coastal, and Ocean Engineering, 136, 27-45. http://dx.doi.org/10.1061/(ASCE)WW.1943-5460.0000023

[14] Rusu, E., Ventura Soares, C. and Rusu, L. (2006) Computational Strategies and Visualization Techniques for the Waves Modeling in the Portuguese Nearshore. Maritime Transportation and Exploitation of Ocean and Coastal Resources, 2, 1129-1136. http://www.taylorandfrancis.com/books/details/9780415390361/

[15] Rusu, E. (2011) Strategies in Using Numerical Wave Models in Ocean/Coastal Applications. Journal of Marine Science and Technology-Taiwan, 19, 58-73. http://jmst.ntou.edu.tw/marine/19-1/58-75.pdf

[16] Butunoiu, D. and Rusu, E. (2012) A Matlab Interface Associated with Modeling Surface Waves in the Nearshore. Journal of Environmental Protection and Ecology, 13, 1806-1817. https://docs.google.com/a/jepe-journal.info/viewer?a=v\&pid=sites\&srcid=amVwZS1qb3VybmFsLmluZm98amVwZS 1qb3VybmFsfGd4OjFIM2I3N2RhMTE2ZTg2ODM

[17] Rusu, L. and Ivan, A. (2010) Modelling Wind Waves in the Romanian Coastal Environment. Environmental Engineering and Management Journal, 9, 547-552. http://omicron.ch.tuiasi.ro/EEMJ/pdfs/vol9/no4/18_2_Rusu_10.pdf

[18] Butunoiu, D. and Rusu, E. (2012) Sensitivity Tests with Two Coastal Models. Journal of Environmental Protection and Ecology, 13, 1332-1350.

https://docs.google.com/a/jepe-journal.info/viewer?a=v\&pid=sites\&srcid=amVwZS1qb3VybmFsLmluZm98amVwZS 1qb3VybmFsfGd4OjQ2MzQyYWNhYjZkZWQ2MTk

[19] Rusu, L. and Butunoiu, D. (2014) Evaluation of the Wind Influence in Modeling the Black Sea Wave Conditions. Environmental Engineering and Management Journal, 13, 305-314.

[20] Holthuijsen, L.H., Herman, A. and Booij, N. (2003) Phase-Decoupled Refraction-Diffraction for Spectral Wave Models. Coastal Engineering, 49, 291-305. http://dx.doi.org/10.1016/S0378-3839(03)00065-6

[21] Mettlach, T.R., Earle, M.D. and Hsu, Y.L. (2002) Software Design Document for the Navy Standard Surf Model, Version 3.2. Naval Research Laboratory, Stennis Space Center, Mississippi, 187. 